\title{
A comparative study of the bone contact to zirconium and titanium implants after 8 weeks of implantation in rabbit femoral condyles
}

\author{
Abdullah Aldosari AlFarraj ${ }^{1,4}$ (D) Anil Sukumaran ${ }^{2}$ Mohammad D. Al Amri ${ }^{1,4}$. \\ AJA Bart Van Oirschot ${ }^{3} \cdot$ John A. Jansen ${ }^{3,4}$
}

Received: 1 November 2016/Accepted: 16 January 2017/Published online: 13 February 2017

(c) The Author(s) 2017. This article is an open access publication

\begin{abstract}
Zirconium ( $\mathrm{Zr}$ ) has been found to have comparable characteristics to titanium with a favorable modulus of elasticity. In addition, the release of $\mathrm{Zr}$-ions of a $\mathrm{Zr}$ implant is supposed to further increase the bone-to-implant response. Therefore, the objective of this study is to compare the bone contact to $\mathrm{Zr}$ and $\mathrm{Ti}$ implants in the femoral trabecular bone of rabbits. In addition, implants provided with a hydroxyapatite (HA) coating were included, as such a coating was proven before to enhance the secondary implant stability. A total of 32 implants consisting of $16 \mathrm{Zr}$ (8 HA coated) and $16 \mathrm{Ti}$ ( 8 HA coated) implants were installed in the femoral condyle of 16 rabbits. After 8 weeks of healing the femoral condyles including the implants were retrieved and studied histologically. The bone-to-implant contact (BIC) percentage was assessed and analyzed statistically. The BIC values of the uncoated $\mathrm{Zr}$ and $\mathrm{Ti}$ implants showed comparable BIC values $(45.1 \pm 14.8$ vs.
\end{abstract}

The original version of this article was revised: The third author name was published incorrectly and it has been updated in this article.

John A. Jansen

john.jansen@ radboudumc.nl

Anil Sukumaran

drsanil@gmail.com

1 Department of Prosthetic Dental Science, College of Dentistry, King Saud University, Riyadh, Saudi Arabia

2 Division of Periodontics, Department of PDS, College of Dentistry Prince Sattam Bin Abdulaziz University, PO Box 153, Alkharj, Riyadh 11942, Saudi Arabia

3 Department of Biomaterials, Radboud University Medical Center, Dentistry 309, PO Box 9101, Nijmegen 6500, HB, The Netherlands

4 Dental Implant and Osseointegration Research Chair, (DIORC), College of Dentistry, King Saud University, Riyadh, Saudi Arabia
$45.5 \pm 13.1)$. The BIC percentage was slightly higher for HA coated $\mathrm{Zr}$ and Ti implants $(60.3 \pm 17.1,59.8 \pm 16.4$, respectively) compared to uncoated, but statistical testing indicated that this difference was not significant. It can be concluded that $\mathrm{Zr}$ and Ti implants show a comparable boneimplant contact after 8 weeks of implantation in the currently used rabbit model. In addition, the deposition of a sputtered HA coating on both $\mathrm{Zr}$ and $\mathrm{Ti}$ implants did not further improve their bone integration.

Keywords Titanium - Zirconium $\cdot$ Calcium phosphate coating $\cdot$ Hydroxyapatite $\cdot$ Osseointegration $\cdot$ Rabbit model

\section{Introduction}

The primary and subsequent secondary stability are the major parameters for the clinical success of oral implants, which is depending on the biological as well as mechanical properties of the used implant material. An implant material has to be corrosion resistant, as characterized by the presence of a thin, passivating oxide layer, which repairs itself rapidly if damaged. Considering the required biomechanical characteristics, the modulus of elasticity of the implant material has to match the modulus of elasticity of bone, which will create a uniform distribution and an adequate reduction of the stresses at the implant-bone interface.

Currently, commercially pure titanium (Ti) is used extensively in the field of oral implantology because of its excellent mechanical strength, corrosion resistance, and good biocompatibility $[1,2]$. These properties are attributable mainly to the formation of a stable titanium oxide layer on the surface [3]. The modulus of elasticity (E-modulus $=$ Young's modulus) of Ti is $116 \mathrm{GPa}$, which is favorable compared with the E-modulus of other 
materials as used for the manufacturing of implants (cobalt-chromium alloy $=200-220 \mathrm{GPa}$, stainless steel $316 \mathrm{~L}=200 \mathrm{GPa})$. Nevertheless, the E-modulus of Ti is still significantly higher than the E-modulus of bone, which ranges $0.5-30 \mathrm{GPa}$ and is determined by the type and anatomical location of the bone tissue (trabecular vs. cortical, limbs vs. vertebral column vs. skull).

Zirconium ( $\mathrm{Zr}$ ) is a metal (in contrast to the ceramic material, zirconia), which is not widely used yet as implant material, but has chemical properties similar to those of $\mathrm{Ti}$ with no local or systemic toxic effects [4]. Although, $\mathrm{Zr}$ is also covered with a very stable and biologically inert oxide layer, the physical and chemical properties, such as oxidation rates, crystal structures, transport properties, water interactions, of the two metals $\mathrm{Ti}$ and $\mathrm{Zr}$ and their oxides differ quantitatively. Further, the E-modulus of $\mathrm{Zr}$ is 88 $\mathrm{GPa}$ and closer to the E-modulus of bone.

Bone is composed of an organic matrix (mainly collagen) and an inorganic component (mainly hydroxyapatite $=\mathrm{HA}$ ). Calcium and phosphate compounds, in different configurations, make up for the major part of hydroxyapatite. However, the inorganic component of bone tissue contains also other inorganic composites, like zinc, strontium, copper, magnesium and fluoride [5]. It has been described that these inorganic trace elements do have osteogenic properties and can replace biological growth factors to influence bone development [6]. Cell culture studies demonstrated that the trace elements had an effect of the proliferation and differentiation of osteoblasts and the resorptive activity of osteoclasts. It was suggested that the bone biological performance of biomaterials can be modified by adding inorganic additives.

In view of the above mentioned, it has also been reported recently that $\mathrm{ZrO} 2$ and $\mathrm{Zr}$-ions are able to promote the proliferation and differentiation of human osteoblasts in vitro $[7,8]$. This effect is supposed to occur by up-regulation of BMP-2 expression and increased signaling. Therefore, we hypothesized that dental implants, manufactured of zirconium, do not only offer a biomechanical advantage but can also further increase the bone-implant response due to the release of $\mathrm{ZrO} 2$ as well as $\mathrm{Zr}$-ions. Therefore, it can be hypothesized that the use of $\mathrm{Zr}$, as implant material, will have a favorable effect on the implant-bone response.

Earlier studies showed already that surface modification of dental implants by the deposition of a synthetic HA coating on titanium can enhance the implant-bone response [9-12]. Hence, the objective of the present study is to analyze and compare the implant-bone response of $\mathrm{Ti}$ and $\mathrm{Zr}$ implants with and without HA coating. Therefore, Ti and $\mathrm{Zr}$ implants with and without HA coating were installed into the trabecular bone of the femoral condyle of rabbits and left in place for 8 weeks. Subsequently, bone-implant contact was assessed by light microscopic evaluation.

\section{Materials and methods}

Sixteen healthy New Zealand White rabbits aged 6-9 months and weighing between 3.5 and $5 \mathrm{~kg}$ were used as experimental animals. All rabbits were housed separately in standard cages under laboratory conditions. The study was approved by the ethical committee of the College of Dentistry, King Saud University. The procedure was based on a well-established bilateral, rabbit, femoral condyle model [13].

\section{Implants}

Thirty-two custom made implants (Machinefabriek Jansen BV, Valkenswaard, The Netherlands) were used for this study. Sixteen of them were made of commercially pure titanium (cpTi). The second group of 16 implants was made of medical grade $\mathrm{Zr}$. The composition of the $\mathrm{Zr}$ is given in Table 1. Half of the implants from both groups were sputter coated with hydroxyapatite [14]. The study group consisted of four different types (8 implants in each group), i.e.: $\mathrm{Ti}, \mathrm{HA}$ coated $\mathrm{Ti}, \mathrm{Zr}$ and $\mathrm{HA}$ coated $\mathrm{Zr}$ implants.

CpTi and $\mathrm{Zr}$ implants The cylindrical implants had the following dimensions: length of implant $8 \mathrm{~mm}$, length of crestal part $1.5 \mathrm{~mm}$, diameter at crestal side $3.5 \mathrm{~mm}$, diameter at apex $2.6 \mathrm{~mm}$, thread depth $0.5 \mathrm{~mm}$, distance between threads $0.5 \mathrm{~mm}$ (Fig. 1). All implants were provided with a minimally rough surface by using a grit-blasting and acid etching procedure $(\mathrm{Ra}=0.5 \mu \mathrm{m})$.

HA coating procedure HA coatings were deposited on the implants by using a commercially available RF sputter deposition system (Edwards ESM 100) [14]. The target material was composed of hydroxyapatite $\left(\mathrm{Ca}_{5}\left(\mathrm{PO}_{4}\right)_{5} \mathrm{OH}\right)$ granules. The $\mathrm{Ti}$ and $\mathrm{Zr}$ implants were mounted on a rotating and water-cooled substrate holder. During

Table 1 The composition of the zirconium

\begin{tabular}{ll}
\hline Type $\mathrm{Zr} 702$ & \\
\hline Elements & Composition (\%) \\
\hline $\mathrm{Zr}+\mathrm{Hf}$ & 99.2 \\
$\mathrm{Hf}$ maximum & 4.5 \\
$\mathrm{Fe}+\mathrm{Cr}$ & $\leq 0.2$ \\
$\mathrm{Sn}$ & - \\
$\mathrm{H}$ & 0.005 \\
$\mathrm{~N}$ & 0.025 \\
$\mathrm{C}$ & 0.05 \\
$\mathrm{Nb}$ & - \\
$\mathrm{O}$ & 0.16 \\
\hline
\end{tabular}



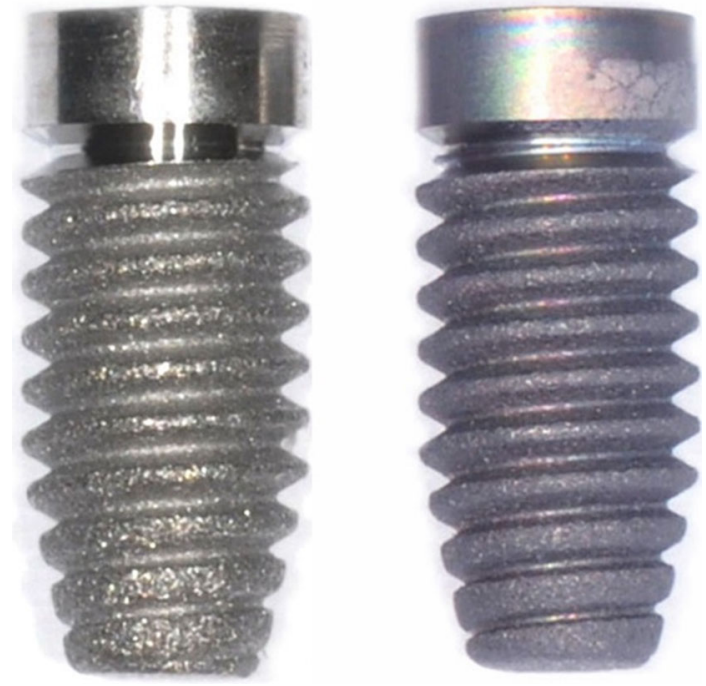

Fig. 1 The type of implants used in the study (Left titanium, Right zirconium)

deposition, the argon pressure was kept at $5 \times 10^{-3}$ mbar and the sputter power was $400 \mathrm{~W}$. After deposition, the coated implants were subjected to an additional infrared heat treatment (HT) for $30 \mathrm{~s}$ at $650{ }^{\circ} \mathrm{C}$ (Quad Ellipse Chamber, Model E4-10-P, Research Inc.). Before implantation, the composition and structure of the coatings were characterized by thin film X-ray diffraction (Philips, PW3710, Almelo, The Netherlands) and Fourier Transform Infrared spectroscopy.

Before surgical installation, all implants (as-received and coated) were autoclaved.

\section{Surgery}

Surgery was performed using aseptic routines, and under general anesthesia by intramuscular injections of a combination dose of $35 \mathrm{mg} / \mathrm{kg}$ ketamine and a dose of $5 \mathrm{mg} / \mathrm{kg}$ xylazine. After anesthesia, the hind limbs were shaved, disinfected and isolated with drapes. Infiltration anesthesia was performed at the experimental sites. The left and right knee joints were exposed through a medial parapatellar longitudinal incision (Fig. 2). The capsule was incised and the medial femoral condyle was exposed after lateral dislocation of the patella. With the knee maximally flexed a hole was created through the articular cartilage into the subchondral bone on the weight-bearing surface of the femoral condyle using a dental drill (type, etc.). Drilling was performed at low rotational speed $(600-800 \mathrm{rpm})$ using extensive external cooling with sterile saline solution. The implant bed was widened in gradient steps with a final drill diameter of $5 \mathrm{~mm}$ twist drill (Nobel Biocare AB, Goteborg, Sweden). The implants were installed with sufficient primary stability ( $\geq 20 \mathrm{Ncm}$ ) using a torque wrench

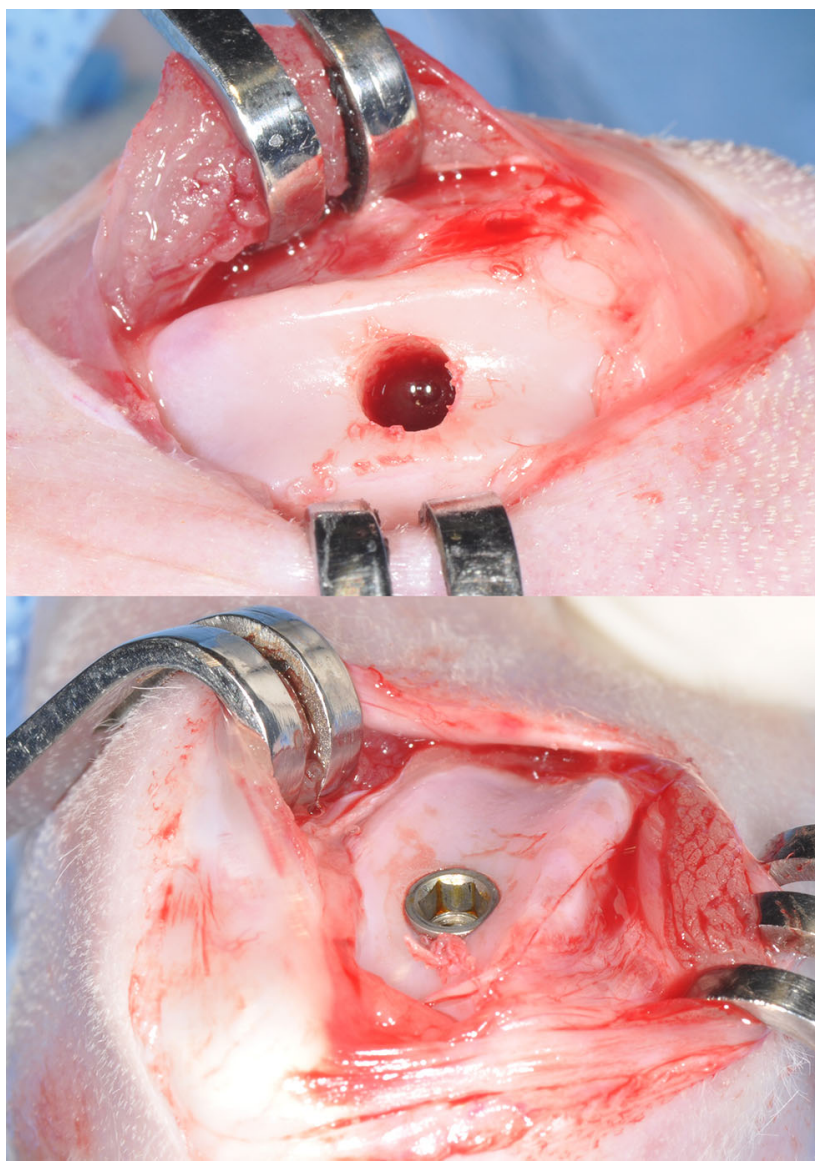

Fig. 2 Pictures show the articular approach, as used for implant installation and final positioning of the implant

(Astra Tech Implant System, Goteborg, Sweden) according a pre-determined randomized sequence, i.e. modified Latin square (Table 2).

Finally, the surgical sites were closed in layers using resorbable sutures (Vicryl, 4-0) and animals were returned to their cages. Post-surgical pain was controlled by the administration Fynadyne ${ }^{\circledR}$ (Fynadine, Schering Plough Animal Health Benelux, Utrecht, the Netherlands) intramuscularly. To reduce the post-operative infection risk Enrofloxacin $5-10 \mathrm{mg} / \mathrm{kg}$ (Baytril, Bayvet Division, Chemagro Ltd, Etobicoke, Ontario) $(5-10 \mathrm{mg} / \mathrm{kg})$ was administered. After 8 weeks of implantation, the animals were euthanized and the femoral condyles were harvested for histological preparation.

\section{Histology}

After harvesting, all specimens were cleaned from attaching soft tissues. The femoral condyles including the implants were fixed in $10 \%$ formaldehyde. After fixation, the specimens were reduced in size and then dehydrated in increasing ethanol concentrations (70-100\%). Finally, they 
Table 2 Randomization schedule

\begin{tabular}{lll}
\hline Rabbit number & Left condyle & Right condyle \\
\hline 1 & $\mathrm{Ti}$ & $\mathrm{TiHA}$ \\
2 & $\mathrm{Zr}$ & $\mathrm{ZrHA}$ \\
3 & $\mathrm{TiHA}$ & $\mathrm{Zr}$ \\
4 & $\mathrm{ZrHA}$ & $\mathrm{Ti}$ \\
5 & $\mathrm{Zr}$ & $\mathrm{ZrHA}$ \\
6 & $\mathrm{Ti}$ & $\mathrm{TiHA}$ \\
7 & $\mathrm{ZrHA}$ & $\mathrm{Ti}$ \\
8 & $\mathrm{TiHA}$ & $\mathrm{Zr}$ \\
9 & $\mathrm{Ti}$ & $\mathrm{TiHA}$ \\
10 & $\mathrm{Zr}$ & $\mathrm{ZrHA}$ \\
11 & $\mathrm{TiHA}$ & $\mathrm{Zr}$ \\
12 & $\mathrm{ZrHA}$ & $\mathrm{Ti}$ \\
13 & $\mathrm{Zr}$ & $\mathrm{ZrHA}$ \\
14 & $\mathrm{Ti}$ & $\mathrm{TiHA}$ \\
15 & $\mathrm{ZrHA}$ & $\mathrm{Ti}$ \\
16 & $\mathrm{TiHA}$ & $\mathrm{Zr}$ \\
\hline
\end{tabular}

$\mathrm{Ti}$ titanium, TiHA titanium coated with $\mathrm{HA}, \mathrm{Zr}$ zirconium, $\mathrm{ZrHA}$ zirconium coated with HA

were embedded (non-decalcified) in modified methylmethacrylate (MMA) for 5 days (mixture of $300 \mathrm{ml}$ MMA, $30 \mathrm{ml}$ Dibutylphthalate, and $5 \mathrm{~g} \mathrm{2,-2}$ 'azabisisobutyronitrile 98\%). After polymerization in MMA, thin sections $(10 \mu \mathrm{m})$ were cut in longitudinal direction to the axis of the implant using an inner circular saw microtome (Leica RM 1600, city, Germany). These sections were stained with methylene blue and basic fuchsin and were used for light microscopic assessment and histomorphometrical analysis.

\section{Histomorphometry}

Histological evaluation was performed using the automated Zeiss Z1 Axio Imager microscope (Carl Zeiss Micro Imaging GmbH, Göttingen, Germany). Histomorphometry was performed using digital image analysis software (Leica $^{\circledR}$ Qwin Pro-image analysis, Leica Microsystems Imaging Solutions Ltd, Cambridge, UK). The quantitative parameter, as assessed, was the percentage of bone to implant contact (BIC \%). Bone contact was analyzed along the total length of the implant; starting at the first coronal micro-thread up to the apex of the implant. BIC \% was defined as the percentage of the implant surface in direct contact with bone without intervening fibrous tissue layers. Separate high resolution RGB (red, green, blue) microscopic images of the stained sections $(10 \times$ objective $)$ containing the complete implants were acquired and stitched. After image binarization and subsequent thresholding the implant from bone, the length of the threaded implant surface was measured (contour of the implant surface was followed) and defined as the maximum possible bone-toimplant contact (BIC). The regions of agreement between the surface outline and the bone were measured as the real BIC parts. Finally, as a result, the BIC percentage was defined.

All measurements were performed for both sides of the implant on three at randomly selected histological sections per implant.

\section{Statistical analysis}

All statistical analyses were performed with GraphPad ${ }^{\circledR}$ Instat 3.05 software (GraphPad Software Inc, San Diego, CA, USA) using one-way analysis of variance (ANOVA) and $t$ test. Tukey-Kramer Multiple Comparisons Test was used to analyze the groups. Differences were always considered significant at $P$ values less than 0.05 .

\section{Results}

\section{Macroscopic evaluation}

All animals survived the experimental period, stayed healthy and showed no sign of infection or discomfort. All implantations sites healed well and no swelling or redness was observed. Gross examination of the retrieved specimens indicated that all implants were in place without any sign of an inflammatory response. The articulating surface of the knee joint had a smooth appearance, but was not completely covered with cartilage. The implant could easily be recognized.

\section{Histological analysis}

No gross differences in bone response were found between the various types of implants under light microscopy (Figs. 3, 4, 5). The implants were surrounded by trabecular bone, as characterized by the occurrence of bone trabeculae with interspersed areas of bone marrow (Figs. 3, 4, 5). The bone trabeculae showed direct contact with the implant surface. Frequently, this contact occurred at the tip of the implant thread. Subsequently, bone was observed to be guided into the implant thread and covered, as a thin layer, the implant surface. No inflammatory cells were seen in the bone-implant interface. The implant bed had completely remodeled and the original drill hole or loosened bone debris could occasionally only be recognized at the cortical side. At the apex of the implant, new bone formation had occurred and when the implant bed was somewhat oversized in length, the created space was always filled with 

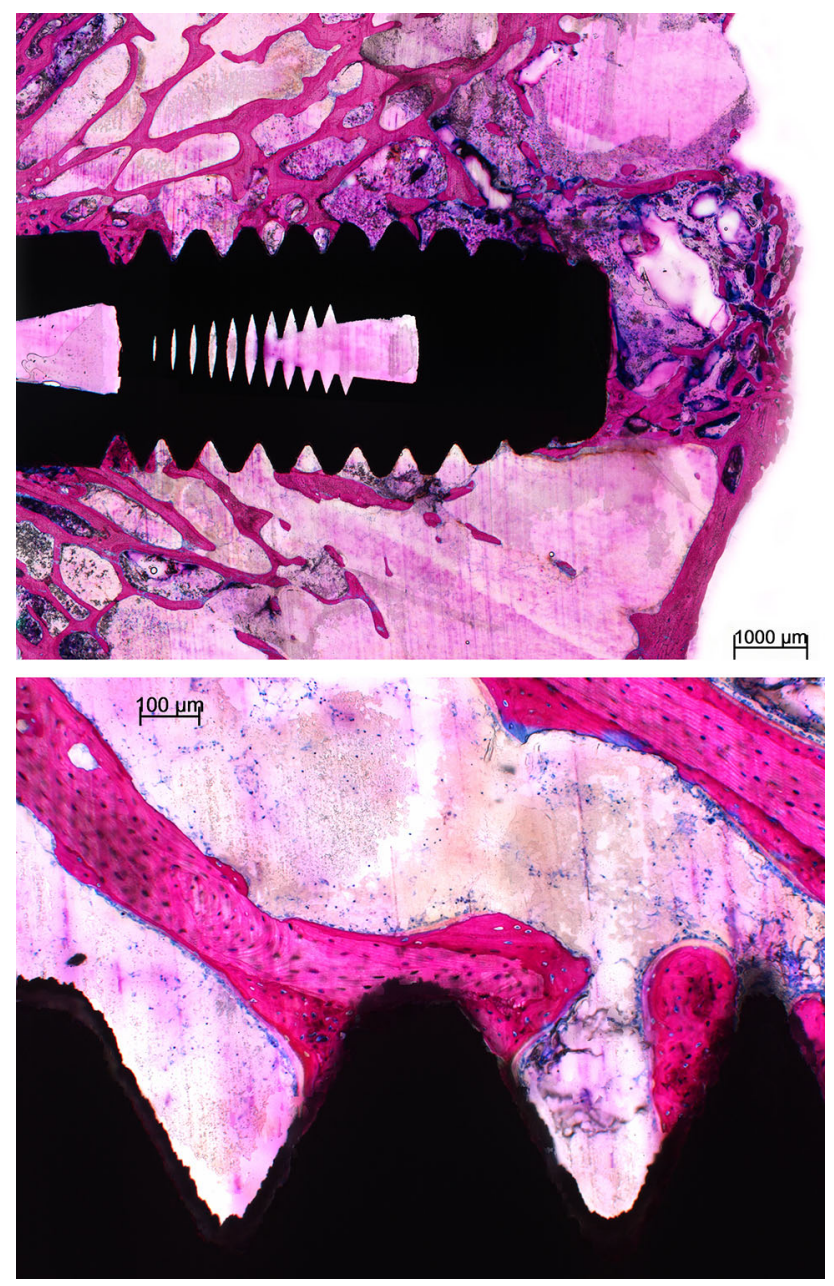

Fig. 3 Light micrographs showing a Ti implant installed into the trabecular bone of the femoral condyle. The implant does not penetrate the growth plate. The bone trabeculae show a tentacle-like contact with the tip of the implant threads

bone tissue. At the cortical side, no or limited marginal bone resorption was observed and no overgrowth of cartilage had occurred (Figs. 4, 5).

\section{Histomorphometry}

The BIC percentage of all four types of implant is depicted in Fig. 6. The BIC percentage of $\mathrm{Zr}$ and $\mathrm{Ti}$ implants showed comparable values $(45.1 \pm 14.8$ and $45.5 \pm 13.1$, respectively). The HA coated $\mathrm{Zr}$ implants had a mean BIC percentage of $60.3 \pm 17.1$ compared to the HA-coated $\mathrm{Ti}$ implants with a mean BIC percentage of $59.8 \pm 16.4$. No statistical significance in BIC percentage existed between the various types of implants. Although, the BIC values seemed to be higher for HA coated $\mathrm{Zr}$ and Ti implants, the observed difference was not statistically significant. Further, it was noticed that the BIC measurements for the respective implant types showed a wide variation.

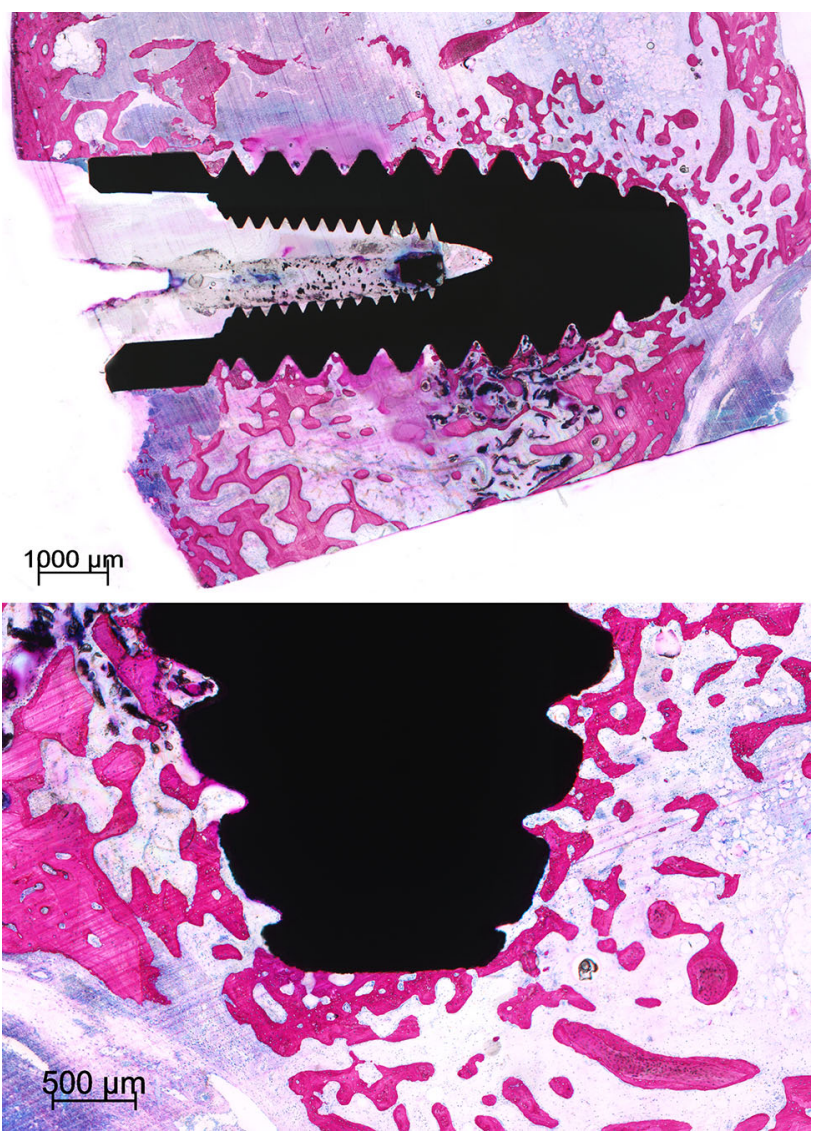

Fig. 4 Histological section of a Ti-HA implant. At the crestal side only limited bone resorption is observed at one side of the implant. At the apex of the implant an abundance of newly deposited trabecular bone is visible. The bone is in close contact with the implant surface without the presence of an intervening fibrous tissue layer

\section{Discussion}

The surface composition of an implant plays an important role in determining the bonding between the implant and the newly formed bone tissue [15]. It determines the cellular and molecular response of osteoblasts and other cells that come in contact with the implant $[10,16]$. Previous publications confirmed that the in vitro response of osteoblasts and osteoclasts was affected by inorganic trace elements [7, 8]. In contrast, this was not observed in our in vivo experimental animal study. Various explanations can be given for this finding, but firstly it has to be noticed that in the cell culture studies relatively large amounts of trace elements were added to the respective culture media. Under in vivo conditions, substantial ion release from the highly passive $\mathrm{Zr}$ material is depending on: (1) the occurrence of shear stresses at the implant-bone interface, which have to trigger the corrosion process, and (2) the $\mathrm{pH}$ found in the tissue surrounding the implant during the initial stages of wound healing [17, 18]. As implant movement in our experimental design is very limited due to the high 

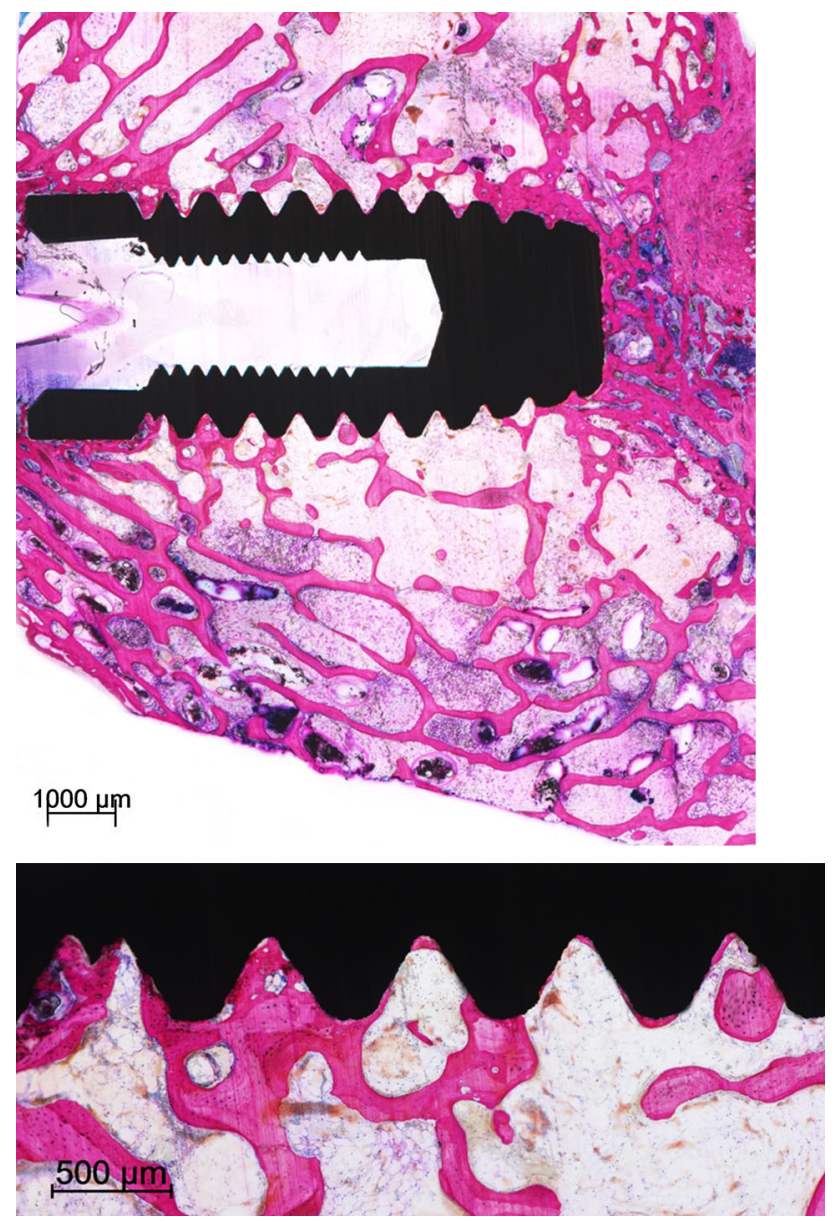

Fig. 5 Light micrographs showing a Zr-HA implant. The implant is positioned into trabecular bone. The trabecular bone seems to be guided into the implant threads. No crestal resorption is observed

initial stability of the implants, a very low ion release and a very low level of $\mathrm{Zr}$-ions can be expected [19]. Also the $\mathrm{ZrO}_{2}$ film, covering the bulk $\mathrm{Zr}$ material, is highly adherent and prevents the release of corrosion products. In addition, a reduction of the $\mathrm{pH}$ of the implant bed will not contribute a lot to an increase of the corrosion rate. It can be supposed that the $\mathrm{pH}$ will already be restored within a few days after surgery to the physiological level due to the used atraumatic surgical procedure.

Our data indicated also that the deposition of an HAcoating on the $\mathrm{Zr}$ as well $\mathrm{Ti}$ implants, did not result in a statistically enhanced bone response. These results do not corroborate with earlier studies, where a similar HA-coating was found to accelerate initial stabilization of implants by enhancing bony ingrowth and stimulating osseous apposition to the implant surface [12, 20-24]. This discrepancy in bone response can be explained by the animal model used in this study and the implant design. Rabbits are known to show a faster skeletal change and bone turnover rate in comparison to large animal models, like

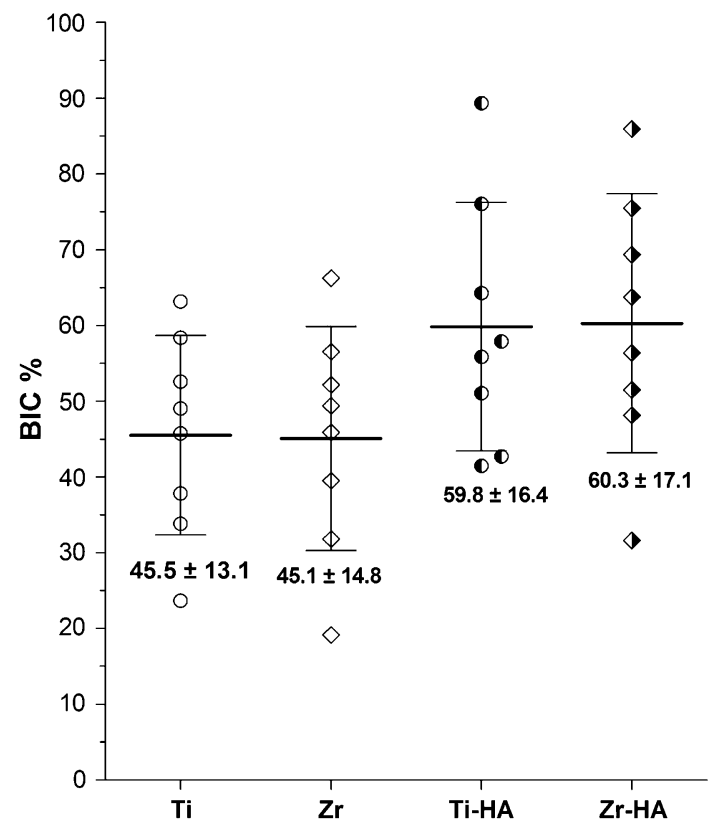

Fig. 6 Bone-to-implant contact percentage (BIC \%) in four types of implants used in the study ( $T i$ titanium, $\mathrm{Zr}$ zirconium, $\mathrm{Ti}-\mathrm{HA}$ titanium hydroxyapatite, $\mathrm{Zr}$-HA zirconium hydroxyapatite). Graph is showing the distribution of the data

goats, dogs and mini pigs [25]. The length of the bone remodeling cycle is 6 weeks in the rabbit compared with about 4 months in humans [26]. In majority of the previous studies, goats were used as experimental animal model and implants were left in place for 6-12 weeks. In these studies, the HA sputter-coated implants always showed an enhanced bone-to-implant contact compared with as-received titanium implants $[9,12,13]$. However, goats are known to show a prolonged bone healing response compared with small experimental animals. As HA-coatings are only able to affect the early bone response, it can be hypothesized that an implantation period of 8 weeks in a rabbit is too long to observe any difference in bone behavior. On the other hand, Hulshoff et al. [27] used rabbits. They installed HA sputter coated implants in the femoral condyle of rabbits and left them in place for 3, 6 and 9 weeks. Plasma-spray HA coated implants were used as reference material and the implant design was completely different. Implants had a cylindrical shape without the presence of screw-threads and were inserted press-fit into the implant bed. This involves that the implant diameter is exactly similar to the implant bed diameter. As a consequence, initial stability of these implants is less compared with the initial stability of a screw-type implant installed in an undersized implant bed. Initial stability affects the process of the secondary stability, which evidently can be overcome by using a bioactive HA-coating. This is also true for the studies, where rats were used and a beneficial effect of a sputtered HA-coating was observed. 
Also, these implants were not provided with screw-threads and were installed in a press-fit mode. As a consequence, the differences in experimental conditions do not allow a straight forward comparison of the various studies. In view of this, it has to be emphasized that researchers should be more focused on the selection of an appropriate animal model and implant design regarding their research question.

Finally, the histological and histomorphometrical analysis showed also that the hypothetically advantageous E-modulus of the $\mathrm{Zr}$ implants did not favor the initial bone response compared with $\mathrm{Ti}$ implants. An articular approach was used in the current study design to install the implants in the trabecular bone on the femoral condyle of the rabbits. This method has advantages over other approaches: (1) the implants are always completely surrounded by trabecular bone, and (2) the implants are loaded by the articulating tibial surface during movement of the rabbit, which mimicks the loading of dental implants during the initial healing phase. The procedure is simple and does not induce serious discomfort for the animals. The histological sections clearly showed that all implants were completely surrounded with trabecular bone without interfering with the growth plate [13]. The disadvantage of this installation approach is that loading condition of the implants is completely different compared with dental implants installed in the alveolar ridge of the maxilla or mandible. Therefore, it is difficult to make a final conclusion about the suggested effect of E-modulus of an implant material on bone behavior. It is recommended that additional studies are done in an animal model and with loading conditions that are more similar to the human clinical situation.

\section{Conclusion}

On basis of the available data, we conclude that $\mathrm{Zr}$ and $\mathrm{Ti}$ show a comparable bone healing response after 8 weeks of implantation in the currently used rabbit model. In addition, the deposition of a sputtered HA coating on both $\mathrm{Zr}$ and $\mathrm{Ti}$ implants did not further improve their bone integration.

\section{Compliance with ethical standards}

Conflict of interest The authors declare that they have no conflict of interest.

Open Access This article is distributed under the terms of the Creative Commons Attribution 4.0 International License (http://crea tivecommons.org/licenses/by/4.0/), which permits unrestricted use, distribution, and reproduction in any medium, provided you give appropriate credit to the original author(s) and the source, provide a link to the Creative Commons license, and indicate if changes were made.

\section{References}

1. Steinemann SG. Titanium-the material of choice? Periodontol. 2000;1998(17):7-21.

2. Krischak GD, Gebhard F, Mohr W, Krivan V, Ignatius A, Beck A, Wachter NJ, Reuter P, Arand M, Kinzl L, Claes LE. Difference in metallic wear distribution released from commercially pure titanium compared with stainless steel plates. Archives of orthopaedic and traumatic surgery. Arch Orthop Trauma Surg. 2004;124:104-13.

3. Galante JO, Lemons J, Spector M, Wilson PD Jr, Wright TM. The biologic effects of implant materials. Journal of orthopaedic research. J Orthop Res. 1991;9:760-75.

4. Piconi C, Maccauro G. Zirconia as a ceramic biomaterial. Biomaterials. 1999;20:1-25.

5. Becker RO, Spadaro JA, Berg EW. The trace elements of human bone. J Bone Joint Surg Am. 1968;50:326-34.

6. Yang L, Perez-Amodio S, Barrere-de Groot FYF, Everts V, van Blitterswijk CA, Habibovic P. The effects of inorganic additives to calcium phosphate on in vitro behavior of osteoblasts and osteoclasts. Biomaterials. 2010;31:2976-89.

7. Chen Y, Roohani-Esfahani SI, Lu Z, Zreiquat H, Dunstan CR. Zirconium ions up-regulate the BMP/SMAD signaling pathway and promote the proliferation and differentiation of human osteoblasts. PLoS One. 2015;10:e0113426.

8. Lee B-A, Kim H-J, Park Y-J, Chung H-J, Kim Y-J. Osteoblastic behavior to zirconium coating on Ti-6Al-4 V alloy. J Adv Prosthodont. 2014;5:512-20.

9. Manders PJ, Wolke JG, Jansen JA. Bone response adjacent to calcium phosphate electrostatic spray deposition coated implants: an experimental study in goats. Clin Oral Implant Res. 2006; 17:548-53.

10. Sista S, Nouri A, Li Y, Wen C, Hodgson PD, Pande G. Cell biological responses of osteoblasts on anodized nanotubular surface of a titanium-zirconium alloy. J Biomed Mater Res Part A. 2013;101:3416-30.

11. Urquia Edreira ER, Wolke JG, Aldosari AA, Al-Johany SS, Anil S, Jansen JA, van den Beucken JJ. Effects of calcium phosphate composition in sputter coatings on in vitro and in vivo performance. J Biomed Mater Res Part A. 2015;103:300-10.

12. Vercaigne S, Wolke JGC, Naert I, Jansen JA. A histological evaluation of $\mathrm{TiO} 2$-gritblasted and $\mathrm{Ca}-\mathrm{P}$ magnetron sputter coated implants placed into the trabecular bone of the goat: part 2. Clin Oral Implant Res. 2001;11:314-24.

13. Alfarraj Aldosari A, Anil S, Alasqah M, Al Wazzan KA, Al Jetaily SA, Jansen JA. The Influence of implant geometry and surface composition on bone response. Clin Oral Implants Res. 2014;25:500-5.

14. Wolke JG, van der Waerden JP, Schaeken HG, Jansen JA. In vivo dissolution behavior of various RF magnetron-sputtered Ca-P coatings on roughened titanium implants. Biomaterials. 2003;24:2623-9.

15. Long M, Rack HJ. Titanium alloys in total joint replacement-a materials science perspective. Biomaterials. 1998;19:1621-39.

16. Martin JY, Schwartz Z, Hummert TW, Schraub DM, Simpson J, Lankford J Jr, Dean DD, Cochran DL, Boyan BD. Effect of titanium surface roughness on proliferation, differentiation, and protein synthesis of human osteoblast-like cells (MG63). J Biomed Mater Res. 1995;29:389-401. 
17. Spector M, Cease C, Tong-Li X. The local tissue response to biomaterials. CRC Crit Rev Bioeng. 1989;5:269-95.

18. Wokalek H, Ruh H. Tissue course of wound healing. J Biomat Applic. 1991;5:337-62.

19. Paquay Y, de Blieck-Hogervorst J, Jansen JA. Corrosion behaviour of metal fibre web structures. J Mater Sci Mater in Med. 1996;7:585-9.

20. Alghamdi HS, Bosco R, van den Beucken JJ, Walboomers XF, Jansen JA. (Osteogenicity of titanium implants coated with calcium phosphate or collagen type-I in osteoporotic rats. Biomaterials. 2013;34:3747-57.

21. Alghamdi HS, van Oirschot BA, Bosco R, van den Beucken JJ, Aldosari AA, Anil S, Jansen JA. Biological response to titanium implants coated with nanocrystals calcium phosphate or type 1 collagen in a dog model. Clin Oral Implant Res. 2013;24:475-83.

22. Caulier H, van der Waerden JP, Paquay YC, Wolke JG, Kalk W, Naert I, Jansen JA. Effect of calcium phosphate (Ca-P) coatings on trabecular bone response: a histological study. J Biomed Mater Res. 1995;29:1061-9.
23. Gottlander M, Johansson CB, Albrektsson T. Short- and longterm animal studies with a plasma-sprayed calcium phosphatecoated implant. Clin Oral Implant Res. 1997;8:345-51.

24. Mohammadi S, Esposito M, Hall J, Emanuelsson L, Krozer A, Thomsen P. Short-term bone response to titanium implants coated with thin radiofrequent magnetron-sputtered hydroxyapatite in rabbits. Clin Implant Dent Related Res. 2003;5:241-53.

25. Castaneda S, Largo R, Calvo E, Rodriguez-Salvanes F, Marcos ME, Diaz-Curiel M, Herrero-Beaumont G. Bone mineral measurements of subchondral and trabecular bone in healthy and osteoporotic rabbits. Skeletal Radiol. 2006;35:34-41.

26. Slaets E, Carmeliet G, Naert I, Duyck J. Early trabecular bone healing around titanium implants: a histologic study in rabbits. J Periodont. 2007;78:510-7.

27. Hulshoff JE, van Dijk K, van der Waerden JP, Wolke JG, Kalk W, Jansen JA. Evaluation of plasma-spray and magnetron-sputter Ca-P-coated implants: an in vivo experiment using rabbits. J Biomed Mater Res. 1996;31:329-37. 